Language and Cognition 9 (2017), 573-602. doi:10.1017/langcog.2016.28

(C) UK Cognitive Linguistics Association, 2016. This is an Open Access article, distributed under the terms of the Creative Commons Attribution licence (http://creativecommons.org/ licenses/by/4.0/), which permits unrestricted re-use, distribution, and reproduction in any medium, provided the original work is properly cited.

\title{
Of the body and the hands: patterned iconicity for semantic categories*
}

\author{
SO-ONE HWANG \\ UC San Diego \\ NOZOMI TOMITA \\ Gallaudet University \\ HOPE MORGAN \\ UC San Diego \\ RABIA ERGIN \\ Tufts University \\ DENIZ İLKBAŞARAN \\ UC San Diego \\ SHARON SEEGERS \\ University of Chicago \\ RYAN LEPIC \\ UC San Diego \\ AN D \\ CAROL PADDEN \\ UC San Diego
}

(Received 16 October 2015 - Revised 09 August 2016 - Accepted 23 August 2016 First published online 08 November 2016)

[*] This work was supported by funding from NIH R01 DC 6473. We thank research assistants Elizabeth Hodgdon, Desiree Hollifield, Ezra Plançon, Diana Andriola, Rehana Omardeen, Jessica Hernandez, Man Manh, Jason Javier, and Emma Washburn. We are also grateful to all participants and the Ha Noi Association for the Deaf for their contributions to the data presented in this project. Address for correspondence: So-One Hwang, Center for Research in Language, University of California, San Diego, 9500 Gilman Dr., MC 5602, La Jolla, CA 92093.e-mail: soone@ucsd.edu 


\section{A B S T R A C T}

This paper examines how gesturers and signers use their bodies to express concepts such as instrumentality and humanness. Comparing across eight sign languages (American, Japanese, German, Israeli, and Kenyan Sign Languages, Ha Noi Sign Language of Vietnam, Central Taurus Sign Language of Turkey, and Al-Sayyid Bedouin Sign Language of Israel) and the gestures of American non-signers, we find recurring patterns for naming entities in three semantic categories (tools, animals, and fruits \& vegetables). These recurring patterns are captured in a classification system that identifies iconic strategies based on how the body is used together with the hands. Across all groups, tools are named with MANIPULATION forms, where the head and torso represent those of a human agent. Animals tend to be identified with PERSONIFICATION forms, where the body serves as a map for a comparable non-human body. Fruits \& vegetables tend to be identified with ов ЈЕст forms, where the hands act independently from the rest of the body to represent static features of the referent. We argue that these iconic patterns are rooted in using the body for communication, and provide a basis for understanding how meaningful communication emerges quickly in gesture and persists in emergent and established sign languages.

K E Y W O R D S : sign language, gesture, iconic strategies, modality, semantic categories.

\section{Introduction}

Sign language researchers have long intuited, albeit with caution, that sign languages tend to be more similar to each other than spoken languages are known to be (Newport \& Supalla, 2000; Pizzuto \& Volterra, 2000; Meier, 2002; Woll, 2003; Perniss, Pfau, \& Steinbach, 2007). While recognizing the need for extensive cross-linguistic research to explore where differences across sign languages lie, researchers have pointed to several possible factors underlying this perceived similarity. One of the most widely assumed and mentioned factors concerns the affordances of the body and the hands for iconic representation in sign languages and in the gestural systems from which sign languages historically emerge.

In one of the earliest investigations of the role of iconicity in sign language structure, Klima and Bellugi (1979, p. 21) compared the signs for 'tree' produced by users of American, Chinese, and Danish Sign Languages. Using what has now become a frequently cited set of examples, they show that while the shape and movement of the hands in each of these signs bears an imagistic 
resemblance to their referent concept, they each comprise quite different formational features, to be described below. Klima and Bellugi use these examples to argue that though the formational features of a sign seem motivated by aspects of its referent, the specific values of those features are unpredictable, resulting in a rich variety of signs across sign languages.

In this paper, we revisit their argument about the unpredictability of signs across different sign languages. We propose an alternate view, that many signs exhibit what we call PATTERNED ICONICITY, even as they individually vary in imagistic form. We propose that it is possible to identify patterns on the basis of which ICONIC STRATEGIES or which combination of strategies are favored for different classes of related entities. We argue that these patterns result from humans using the body and the hands to create and organize a lexicon.

To illustrate patterned iconicity, we return to Klima and Bellugi's (1979) discussion of the signs for 'tree' across different sign languages. In Figure 1a, 'tree' is represented by vertically holding up the dominant hand with spread fingers and placing the elbow on the other hand, which is positioned horizontally. In addition to American Sign Language, other languages that have forms similar to this include Brazilian, British, French, German, Greek, Icelandic, Lithuanian, Portuguese, Russian, Turkish, and Spanish Sign Languages. All examples are drawn from an online dictionary <www.spreadthesign.com>. Engberg-Pedersen (2004) corrects the record and reports that the Danish Sign Language sign for 'tree' is also represented in this way (see <www. tegnsprog.dk>), unlike what Klima and Bellugi (1979) describe. In Figure 1b, 'tree' is represented with a two-handed symmetric upward motion of the hands. Languages that use a variant of this form include Chinese (Klima \& Bellugi, 1979) as well as Indian and Italian Sign Languages. While the formational features of the signs in Figure 1a and $1 \mathrm{~b}$ differ, they both use the hands and arms away from the body (that is, away from the head and torso) to represent a static aspect of the shape of the referent, either the trunk and the branches, or only the shape of the trunk. Both examples exemplify the strategy we call о в J E C T.

In contrast, two common forms for 'bird' in the same online dictionary coordinate the body with the hands to represent aspects of the referent. In Figure 2a, 'bird' is represented by contacting the dominant hand with the front of the mouth, and with the index and thumb opening and closing like a beak. Languages that use a variant of this form include American, Austrian, Brazilian, British, Czech, French, Icelandic, Italian, Japanese, Latvian, Lithuanian, and Swedish Sign Languages. In Figure 2b, 'bird' is represented by flapping the hands and arms at the sides of the body. Languages that use a variant of this form include Turkish, German, Estonian, and Polish Sign Languages. Several sign languages also use the two forms together in 
a

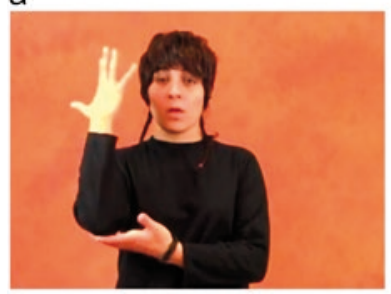

b

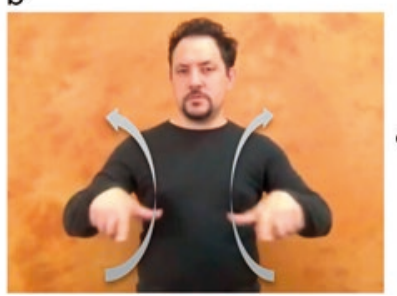

common forms for 'tree' in sign languages

Fig. 1. The above signs for 'tree' are similar to the iconic forms described by Klima and Bellugi (1979). Both images are from <www.spreadthesign.com>, with (a) from Greek Sign Language and (b) from Italian Sign Language.

sequence: Russian, Portuguese, Spanish, Bulgarian, Ukrainian, Indian, and Ugandan Sign Languages.

The forms in Figures $2 \mathrm{a}$ and $2 \mathrm{~b}$ have different hand configurations, locations, and movements, but in this paper we view them as instances of the same iconic strategy, which we call PERSONIFICATION, mapping the body of a non-human entity onto the human body, using the human head to represent parallel locations on a non-human head, the human body to represent a non-human body, and human appendages to represent nonhuman appendages. These signs for 'bird' differ from the earlier examples of signs for 'tree' because, in both signs for 'bird', the bird's body is superimposed or mapped onto the body of the signer - its mouth is the signer's mouth; its wings are the signer's arms - while in no sign language that we know of does a person's body become the body of a tree in a lexical sign (except when purposely creating an anthropomorphic tree in artistic performance, for instance).

Two common forms for 'comb' in the same online dictionary exemplify another strategy for encoding meaning that recruits the body for iconic representation. Padden and colleagues (2013) noted that for hand-held, manmade tools like 'comb', sign languages typically use one of two iconic strategies, referred to together here as MANIPULATION. In Figure 3a, the hand is configured like the human hand holding a comb, moving near the head and simulating the action of combing one's hair; in this sign, the signer's head, arm, and body represent a human head, arm, and body. Languages that use a variant of this form include Austrian, British, Czech, French, German, Indian, Italian, Japanese, Norwegian, Spanish, and Turkish Sign Languages. In Figure $3 b$, the hand is configured to resemble the teeth of a comb, also moving near the head simulating a combing motion. Languages that use a variant of this form include American, Estonian, Latvian, Lithuanian, Polish, Portuguese, Russian, Swedish, and Ukrainian Sign Languages. Again, unlike the signs for 'tree', in the signs for 'comb', the signer's body plays an iconic role of representing the body of an agent manipulating the referent in 
a

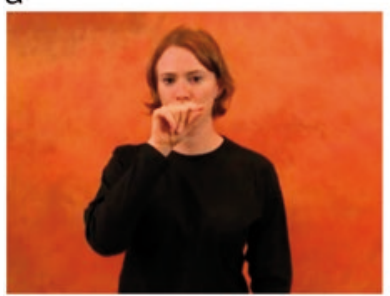

b

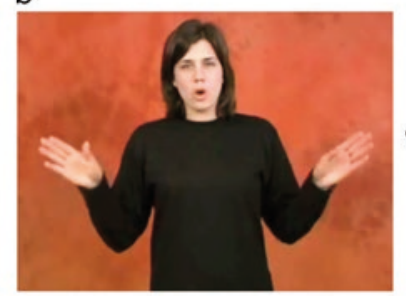

common forms for 'bird" in sign languages

Fig. 2. The signs represent 'bird' with a shared iconic strategy in which the human body maps to the body of a non-human entity. Both images are from <www.spreadthesign.com>, with (a) from American Sign Language and (b) from German Sign Language.

both variants. Unlike tree and bird, which are natural entities, a comb is a man-made artifact to be used for a specific function. The MANIPULATION forms in Figure 3 both reflect humans' cultured interactions with these objects. As might be expected, we find that across different sign languages and cultures, the way the body and the hands are used reflect common practices, but they are consistently MANIPULATION forms.

We regard the body as more than just a place of articulation for the hands, but critically involved in making meaning. The body can be used to explicitly represent agency and animacy, and purposely de-emphasized or excluded to represent non-agency and non-animacy (cf. Meir, Padden, Aronoff, \& Sandler, 2007). To review, the key iconic strategies we discuss here are: MANIPULATION, which further divides into two: (i) "INSTRUMENT", in which the hands depict the size and shape of an object, and (ii) "H A N D L I N G", in which the hands show how an object is held by human hands. We make a distinction between the INSTRUMENT strategy and a similar one which we term ов ЕСт, where the configuration and movement of the hands depict the size and shape of an object and the role of the body is purposely de-emphasized. As we discuss below, this distinction is crucial for marking humanness. And finally, we further distinguish INSTRUMENT and O B JECT strategies from PERSONIFICATION, where the hands depict the size and shape of specific parts of non-human animate entities whose bodies are represented by signers' or gesturers' bodies.

We describe patterned iconicity as made up of iconic strategies grouped together to form distinct patterns that are consistently used by gesturers and signers. Our work echoes Kendon's (1980, p. 97) earlier insight about the nature of iconicity in gesture, that "certain kinds of referents tend to favor certain kinds of realization devices". Others have discussed referent-realization device pairings in gesture and sign languages under a variety of terms, focusing on the representational role of the hands, in particular whether the hands are shaped to represent human hands or to represent the referent 
a

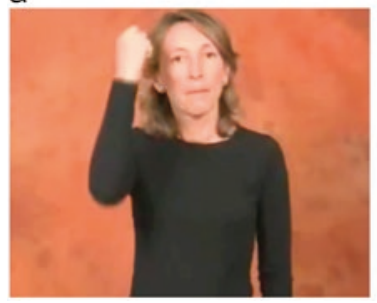

b

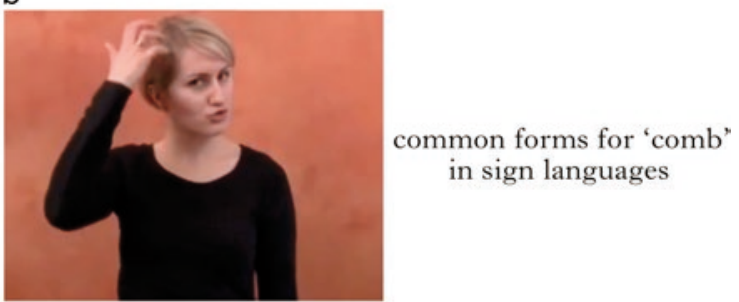

Fig. 3. The signs represent 'comb' with a shared iconic strategy in which the human body maps to the body of a human agent. Both images are from <www.spreadthesign.com>, with (a) from Spanish Sign Language and (b) from Polish Sign Language.

(Goodglass \& Kaplan, 1963; Supalla, 1982; Brentari, Coppola, Mazzoni, \& Goldin-Meadow, 2012; Müller, Bressem, \& Ladewig, 2013). Padden, Hwang, Lepic, and Seegers (2015) and others (Goldin-Meadow, So, Özyürek, \& Mylander, 2008; Brentari, Renzo, Keane, \& Volterra, 2015; Strickland, Geraci, Chemla, Schlenker, Kelepir, \& Pfau, 2015) use the different responses of non-signing gesturers compared to signers as indicative of emergent properties of spontaneous gesture and sign languages. The comparison across groups provides an opportunity to examine possible pathways for grammaticization and conventionalization from emergent to established sign language lexicons and grammars.

Here we seek to sharpen our earlier observations (Padden et al., 2015) by examining in detail the ways in which gesturers and signers use iconic patterning to distinguish between entities having different properties of instrumentality, animacy, and humanness. As in our earlier work, we view these iconic strategies as being grounded in the body, as both the seat of sense and proprioceptive knowledge, and a readily available and portable medium of cultured interaction and communicative expression.

We propose that, when asked to identify and name pictures of entities, gesturers and signers consistently draw from the same set of strategies to form distinct iconic patterns marking different semantic categories: (i) tools are man-made artifacts, (ii) animals are natural entities that are non-human and animate, and (iii) fruits \& vegetables are natural, inanimate entities. To test this, we code gesture and sign forms produced by gesturers and signers involving each of the body's four partitionable zones (Dudis, 2004) - the head, the torso, and each of the arms. We evaluate, first, whether the forms produced by gesturers and signers reliably use each of the iconic strategies we have named here, then second, whether our coding of their strategies can reveal important differences between gesturers and signers of different sign languages. We next examine what these results suggest about pathways to grammaticization and conventionalization in a sign language. 


\section{Overview of the studies}

We examine lexical signs produced by deaf signers of eight different languages, as well as the gestures without speech produced by hearing American nonsigners during a picture task. All participants were shown photographs of thirty tools, thirty animals, and thirty fruits and vegetables. Signers were asked to name the pictured object in their language, and non-signers were asked to identify the pictured object using their hands and body instead of their voice. As we explain below, some of the languages that we report on are recently identified and young, and dictionaries are not yet available for them.

For the main study, the GROUP ELICITATION STUDY, we collected responses from eight individuals in four groups: (i) hearing undergraduate students in the US who reported no experience using a sign language; (ii) adult signers of a village sign language that was recently identified in the Central Taurus Mountains of Turkey, called Central Taurus Sign Language (CTSL). It is estimated to be less than 100 years old and is currently the primary means of communication for sixteen deaf signers living in nearby villages and their hearing family members (Ergin, 2015); (iii) signers of American Sign Language (ASL); and (iv) Japanese Sign Language (JSL, also known as Nihon Syuwa). The latter two sign languages are unrelated and each are 200 or more years old.

In a follow-up study, the S INGLE ELICITATION STUDY, we confirm the results from the group elicitation study for a single signer from each of the additional unrelated sign languages: Al-Sayyid Bedouin Sign Language in the Negev area of Israel (ABSL), Israeli Sign Language (ISL), and German Sign Language (DGS, Deutsche Gebärdensprache). ABSL and ISL, like CTSL, are emerging languages and reported to be less than 100 years old (see Meir, Sandler, Padden, \& Aronoff, 2010, for a comparison of ISL, which is described as a deaf community sign language, and ABSL, as a village sign language). DGS, like ASL and JSL, is an established sign language and approximately at least 200 years old. Our goal is to confirm or disconfirm whether the same strategies can be found in individual signers of three more sign languages that are each unrelated to one another.

In a third study, the CORPUS STUDY, we extend our analysis to include different entities for each of the three semantic categories, and more culturally specific referents than those from our elicitation task. We drew from a lexical corpus of Kenyan Sign Language (KSL), compiled by one of the co-authors (H. Morgan) based on fieldwork, and a dictionary of Ha Noi Sign Language (HNSL). KSL is an indigenous sign language of Kenya that emerged from two deaf schools established in western Kenya in the early 1960s. HNSL is a regional sign language of Vietnam belongs to the same language family as 
Ho Chi Minh City (Saigon) Sign Language and Hai Phong Sign Language (Woodward, 2000). Before the partition of Vietnam in 1945, deaf people from all over Vietnam attended the deaf school near Ho Chi Minh City that was founded in 1886 (Woodward, Nguyen, \& Tien Nguyen, 2004). The first deaf school in north Vietnam was established in Hanoi in 1976. Based on what is known about the histories of deaf schools in each of these languages, KSL and HNSL are likely younger than ASL and JSL.

In the following sections, we describe the experimental materials in more detail, the coding system for identifying iconic strategies, and the rates at which these strategies were found for each group and semantic category. The results are presented in three parts, consisting, first, of the group elicitation (American gesturers, CTSL, ASL, and JSL), then the single elicitation (ABSL, ISL, and DGS), and finally, the corpus study (KSL and HNSL). We show that, despite individual variation in the specific forms of the elicited signs and gestures, there nevertheless are reliably identifiable patterns that signers and gesturers use for entities drawn from each of the three semantic categories we identify here.

\subsection{PART I C I PAN T S}

Thirty-two participants from four groups of subjects ( 8 participants each) participated in the group elicitation study. Eight hearing non-signers were recruited and tested at the University of California, San Diego. These nonsigners are referred to here as the Gesture group. The participants in the Gesture group are undergraduate students at a diverse university, and are native speakers of a comparably diverse range of languages; however, as students at an American university, they use English on an everyday basis. All participants in the Gesture group were tested in a monolingual spoken English setting and reported that they had no knowledge of a sign language. We acknowledge that testing groups of homogeneous speakers of different languages, as reported in Padden et al. (2013) and Brentari et al. (2015), could be a future extension for more in-depth understanding of cross-cultural variation in gesture patterns. However, such a goal is beyond the scope of the present study. Our primary criteria for selecting Gesture participants were lack of signing experience and willingness to create silent gestures to name or identify objects shown in pictures.

The remaining twenty-four participants self-identify as deaf or hard-ofhearing and use a sign language in their everyday life. Eight signers of ASL were tested in the US. Eight deaf signers of JSL were tested: seven in Japan and one in the US. Eight deaf signers of CTSL were tested in Turkey in the village where they live. All signing participants were tested in their respective sign languages, by a mixture of deaf and hearing experimenters. Due to the 
heterogeneous nature of each of these signing communities, and because ontogenetic sources of variation was not the focus of our study, we did not explicitly control for factors such as age of acquisition here. All participants were able to complete our vocabulary elicitation task on the basis of their sign experience.

In the single elicitation study, we tested one deaf signer each of ABSL, ISL, and DGS using the elicitation materials described below. In the corpus study, the data of KSL and HNSL were obtained from lexical datasets that had been independently compiled prior to our study.

\subsection{MATERIALS AND PROCEDURE FOR GROUP AND SINGLE ELICITATION STUDIES}

For the group and single elicitation studies, all participants were tested using the same materials and following the same procedure. Participants were informed that they would see several photographs, and that they should name or identify the item in each picture. All signers were instructed to sign in their own languages. The gesturers were instructed to complete the task using their hands and body instead of speaking, and to remain seated throughout the task.

Each participant had a 2 -item practice session followed immediately by the 90 -item picture naming task. All items were represented digitally as individual photographs of a single item against a white background. Participants directed their responses to an experimenter and were allowed to proceed at a natural and comfortable pace. Each session with a participant was recorded as continuous digital video.

The practice items were cup and eggs. After the practice items, participants were given feedback such as to only name or identify the object, and not to describe it in detail or to develop a narrative around the object. The test items were presented to each participant in a single, randomized block, comprising of three conditions with thirty entities each: tools, animals, and fruits \& vegetables. Tools consisted of: broom, cellphone, cleaver, comb, fork, hairbrush, hairdryer, hammer, handsaw, key, knife, lipstick, mascara, mop, nail polish, paintbrush, paper fan, pencil, plug, rake, screwdriver, shovel, spoon, staple remover, thermometer, toothbrush, turner (spatula), umbrella, vacuum, wrench. Animals consisted of: alligator, ant, bear, bee, bird, bunny, butterfly, cat, chicken, cow, dog, dolphin, duck, elephant, fish, frog, giraffe, goat, horse, lion, monkey, mouse, owl, scorpion, shark, sheep, snake, spider, turtle, whale. Finally, fruits \& vegetables consisted of: apple, avocado, banana, bean sprouts, cabbage, carrot, cashew, cauliflower, cherry, chili, corn, eggplant, garlic, ginger, grape, grapefruit, green beans, green onion, mango, onion, orange, peach, pear, pineapple, potato, snap pea, strawberry, sweet potato, tomato, watermelon. 


\subsection{CODING AND ANALYSIS}

All participants' videotaped responses from the group and single elicitation analyses were coded using the ELAN annotation software developed at the Max Planck Institute for Psycholinguistics in Nijmegen (Brugman \& Russel, 2004). Their responses were first segmented in time if there was more than one sign or gesture in the response. Each segmented response was analyzed in terms of the participant's reference to the body, the head, the right arm and hand, and the left arm and hand. The body was coded for whether it represented (i) the body of a human agent acting upon the referent, (ii) the body of the referent, or (iii) neither an agent nor the referent. The head was coded for whether it represented (i) the head of a human agent acting upon the referent, (ii) the head of the referent itself, (iii) to represent something other than a human head, or (iv) none of the above. Each arm was coded for whether it represented (i) the arm of a human agent acting upon the referent, (ii) a part of the referent, or (iii) the referent itself without a simulated human action.

The three principal iconic strategies that emerged from compiling the data together were manipulation, personification, and object, as previously discussed. The MANiPULATION strategy involves the body representing the body of a human agent and an arm representing the arm of a human agent as it acts upon the referent, as in Figure 4a. Previously, we distinguished between the HANDLING strategy (as in Figure 3a), where the signer's hand represents a human hand in action, and IN STRUMENT strategy (as in Figure 3b), where the signer's hand additionally profiles the shape of the referent tool (Padden et al., 2013, 2015). Our distinction between the two iconic strategies can also be found in work by others (Goodglass \& Kaplan, 1963; Overton \& Jackson, 1973; Boyatzis \& Watson, 1993; O’Reilly, 1995; Brentari et al., 2012, 2015). Here, we collapse the two strategies together as M A N I P U LAT I ON to highlight their common property, that the signer's body represents the body of a human agent using the referent, and that the form includes motion of the signer's arm representing human action. The PERS ONIF I CATI ON strategy involves the body representing the body of the referent and an arm representing a part of the referent, as in Figure $4 \mathrm{~b}$. The OBJECT strategy involves an arm representing the referent itself without simulated human action, as in Figure 4c. Within the general о в J Е C T strategy we include forms where the configuration of the hand represents the shape of an object (a "manual sculpture”, Müller et al., 2013), and a T R A C I N G strategy where the movement of the fingers or the hand(s) outline the shape of an object (Padden et al., 2013). In both cases, as in the example of 'tree', the body parts do not map to a human agent. In other words, our classification of iconic strategies uses a relatively broad stroke in order to identify common 
a

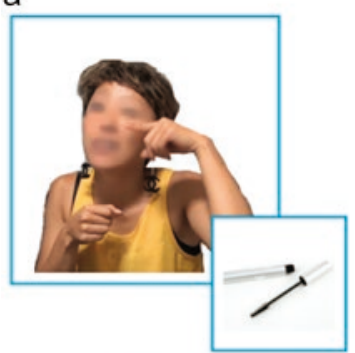

JSL 'mascara' MANIPULATION strategy b

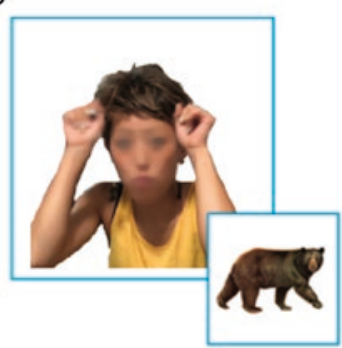

JSL 'bear' PERSONIFICATION strategy
C

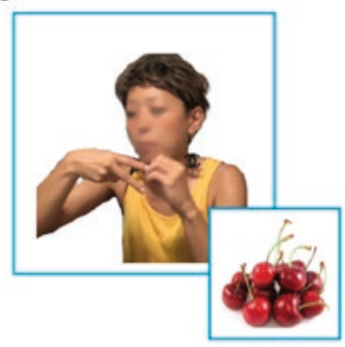

JSL 'cherries' OBJECT strategy

Fig. 4. Signs from Japanese Sign Language, coded for strategy.

properties behind groups of signs and gestures, focusing principally on the role of the body in iconic representation. In individual responses, the forms are coded based on whole sign/gesture form-meaning mappings that include both movement and handshape (not just handshape, as in Brentari et al., 2012, 2015) and the relationship of the hands to the rest of the body.

Some responses consisted of multiple sequential parts. Multiple responses to a single entity were each coded. For example, in response to the test item 'horse', one gesturer first moved her hands to both sides of her head to represent an animal's ears (body as body of referent, arms as parts of the referent), then moved her hands to the front of her body to act out grasping the reins of an imagined horse (body as body of human agent acting on the referent, arms as arms of a human agent acting on the referent). These two segments were analyzed first as P E R S O N I F I C A T I ON then M A I P ULAT I ON. In the case of a response for 'cabbage', as shown in Figure 5, a CTSL signer first showed the round shape of a cabbage (arms as referent itself without simulated human action), followed by a chopping motion (body as body of human agent acting on the referent, arms as arms of human agent acting on the referent). These two segments were analyzed as ОВ ВЕст and MANIPULATION.

The coding decisions for different parts of the body sometimes were congruous; for example, if the participant's body is representing the body of a human agent manipulating the referent, then it is often the case that the participant's head is also representing the head of a human agent. However, our coding system also allowed us to capture responses in which different parts of the body played different representational roles. For example, some responses used each of the arms differently. In the ASL sign for 'sheep', the non-dominant arm represents the sheep's body (arm as a part of the referent), while the dominant arm maps to the human action of using shears to remove 


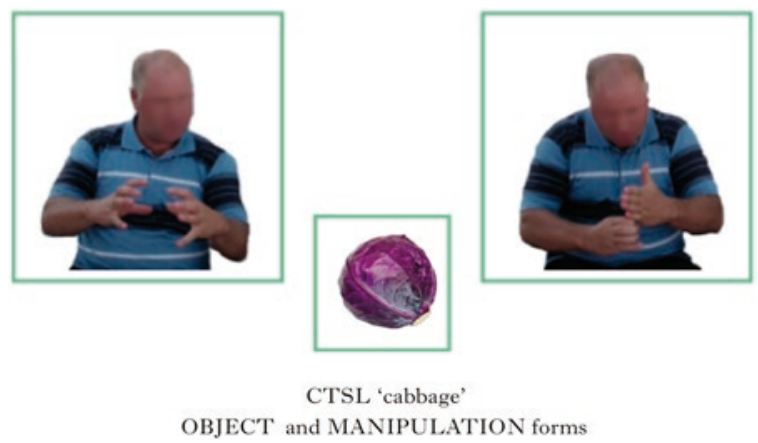

Fig. 5. Example from a signer of Central Taurus Sign Language using two different strategies for 'cabbage', оBJECT and MANIPULATION.

wool (arm as arm of human agent acting on the referent). In this instance, a single segment of a response was coded for two iconic strategies used simultaneously, MANIPULATION and PERS ONIFICATION. In such cases, as described below, the form was counted once for each iconic strategy.

Our coding system also accommodates examples of signs or gestures where parts of the head and face, including the nose, lips, and eyes, are associated with inanimate objects, but are not counted as examples of any of the three iconic strategies we identify. For example, in the ASL sign for 'cabbage' (Figure 6), the head resembles a spherical object and the hand resembles a leaf (head as something other than a head, arm as part of the referent) (Shaw \& Delaporte, 2015). In other examples, parts of the head or face were used to represent sensations (the mouth used to represent a pained human mouth in JSL 'chili pepper') or shapes (the nose used to represent a triangular shape in JSL 'strawberry') or textures (the cheek used to represent fuzzy skin in ASL 'peach'). The use of these additional strategies suggests to us that there are many more that we have yet to identify and classify, and that, in a more detailed analysis of the head and face, we may find a rich environment for describing specific cross-linguistic distinctions across sign languages. Here we limit our discussion to the major strategies of MANIPULATION, PERSONIFICATION, and OBJECT.

Finally, in ASL, JSL, and ISL, some responses for referents involved fingerspelling the name of the object in the dominant spoken language. Because fingerspelling does not draw from the same iconic resources as signs, we put aside all fingerspelled segments and did not include them in any category.

Reliability of the coding was assessed on data from four randomly chosen participants, one from gesture, CTSL, ASL, and JSL groups. There was agreement on the coding for $96 \%$ of the test stimuli. 


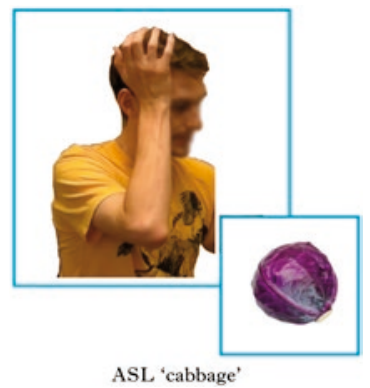

Fig. 6. Example from American Sign Language, where the head does not represent a head as a body part but rather a round object.

In our discussion of the results, for each group, we report the mean average percent of use of an iconic strategy for items in a semantic category. Because the response to a referent could involve more than one strategy (e.g., gesture for 'horse', ASL sign for 'sheep' as described above), the percentages do not necessarily sum to $100 \%$.

\section{Results and discussion}

\subsection{GROUP ELICITATION STUDY}

Here, we focus on the results from Gesture, CTSL, ASL, and JSL, with data from eight individuals in each group. The results for tools are shown in Figure 7, for animals in Figure 8, and for fruits and vegetables in Figure 9. We examined whether the semantic category of referents are predictive of the iconic strategy that is preferentially used to represent them. To test this claim, we examined whether or not there was a dominant, or highly preferred, strategy for representing each semantic category.

Based on our previous findings (Padden et al., 2013, 2015), we expected that the MANIPULATION strategy would be the dominant way to represent tools in our test items. The majority of our total of thirty tools were the same entities used in our earlier study (Padden et al., 2013). Indeed, in this study most tools were represented using MANIPULATION forms: $96 \%$ in Gesture, 95\% in CTSL, 97\% in ASL, and 99\% in JSL (Figure 7a). We did not find any cases where tools were represented using PERSONIFICATION (Figure 7b), though hypothetically, an entity like 'hammer' could be shown by bending the torso in a downward swinging motion. Anthropomorphic forms like these are found in poetry and storytelling in sign languages to attribute animacy and emotion to inanimate entities, but not as vocabulary signs (Sutton-Spence \& Napoli, 2010). We did find cases where tools were represented with овЈЕСТ forms, either alone or in sequence with 
A) MANIPULATION

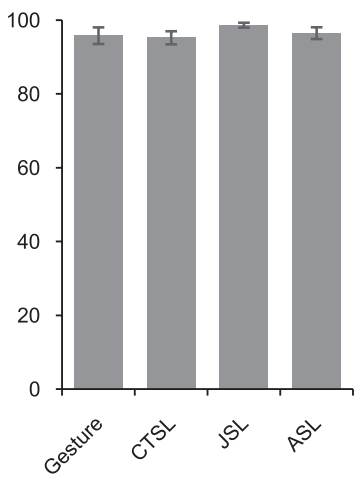

B) PERSONIFICATION

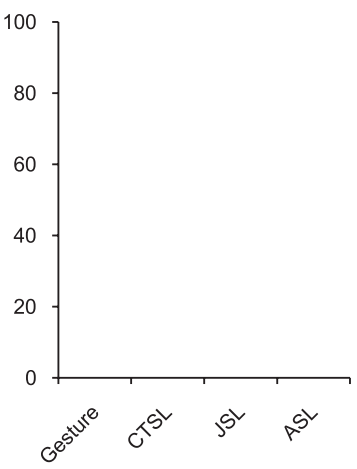

C) OBJECT

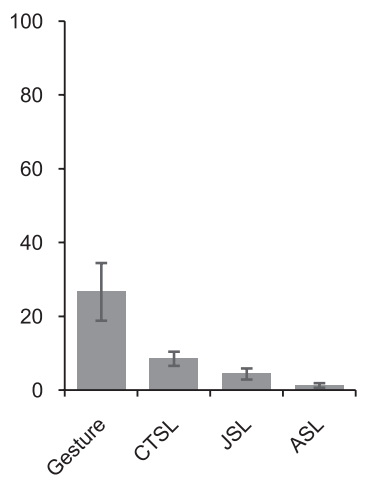

Fig. 7. Graphs demonstrate that all four groups show a preference for MANiPUlation forms over other forms for representing tools. (The values reflect mean averages across eight participants in each group with standard error bars.)

MAN IPULATI ON forms: 27\% in Gesture, 9\% in CTSL, 1\% in ASL, and 4\% in JSL (Figure 7c).

We predicted that the PE R S O N I F I C A T I O N strategy would be the dominant way to represent animals, as shown in the sign language examples for 'bird' across different sign languages. In fact, PERSONIFICATION forms were used for entities in the animal category at the following rates: $74 \%$ in Gesture, $67 \%$ in CTSL, 65\% in ASL, and 68\% in JSL (Figure 8b), and were never used to refer to fruits \& vegetables or tools (Figures $7 \mathrm{~b}$ and $9 \mathrm{~b}$ ). Our results show that the use of the PERSONIFICATION strategy with animals is attested cross-linguistically as a preferential pattern, but it is not as exclusive as the robust use of MANIPULAT I ON strategy with tools. For animals, gesturers and signers used ов в Е С T forms as well (Figure 8c), either alone or in combination with PERSONIFICATION.

The variation in representing animals with PERSONIFICATION and OBJECT forms may have been due to the thirty photographs of animals selected for the elicitation, which included mammalian vs. non-mammalian, terrestrial vs. aquatic, large vs. small, and wild vs. domesticated entities. Many-legged insects, for example, may be more likely to recruit the о в JE C T strategy because of their smaller size and the difficulty of mapping onto the human body, as in an observed gesture for 'scorpion' (Figure 10), which we coded as an овјЕст form. We observed that such овЈЕст forms occurred for animals at the following rates: $43 \%$ in Gesture, $46 \%$ in CTSL, 


\section{GROUP ELICITATION STUDY \\ ERCENT OF ANIMAL CATEGORY REPRESENTED BY}

A) MANIPULATION

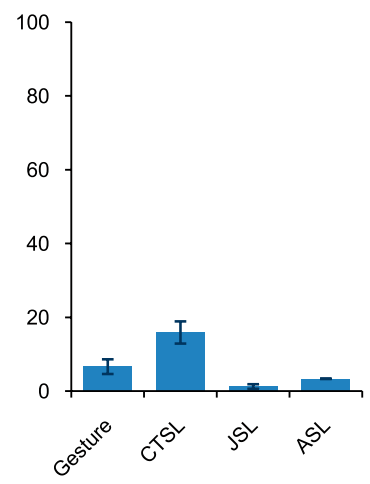

B) PERSONIFICATION

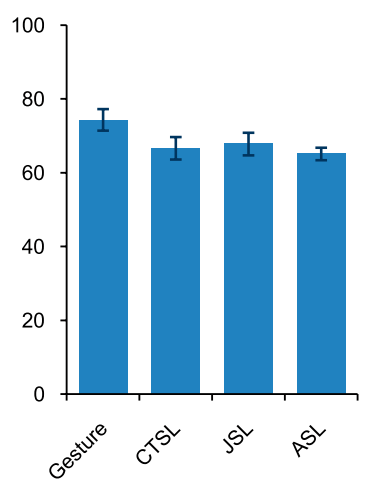

C) OBJECT

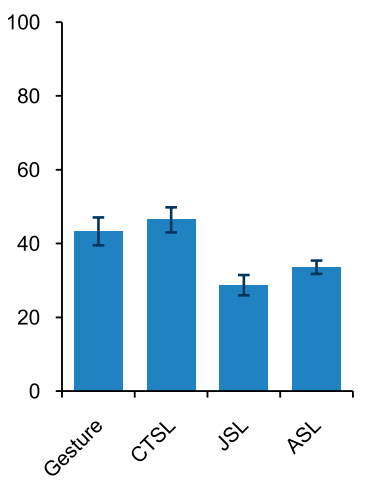

Fig. 8. Graphs demonstrate that all four groups show the highest preference for PERSONIFICATION forms for representing animals, with lower preferences for OBJECT and MANIPULATION forms. (The values reflect mean averages across eight participants in each group with standard error bars.)

$34 \%$ in ASL, and $29 \%$ in JSL (Figure 8c). MANIPULATION rates were low for animals: $7 \%$ in Gesture, $16 \%$ in CTSL, 3\% in ASL, and 1\% in ASL (Figure 8a).

We predicted that the овJECт strategy would be a common way to represent fruits \& vegetables. The rates for овJест forms were: $67 \%$ in Gesture, $76 \%$ in CTSL, $37 \%$ in ASL, and $58 \%$ in JSL (Figure 9c). Although the rate of ов Вест forms were the highest for fruits \& vegetables compared to the other categories, the use of the ов ВЕС T strategy for fruits \& vegetables was not as robust as the use of MANIPULATION for tools and PERSONIFICATION for animals. MANIPULATION forms were observed at higher rates than ов Еест forms for fruits \& vegetables in Gesture (93\%) and CTSL (75\%) (Figure 9a). None of the three principal iconic strategies discussed here emerged as a dominant pattern for fruits \& vegetables in ASL.

Statistical differences in the rate of observed instances of the iconic strategies for each of the semantic categories as described above were captured through the Wald test on binomial logistic regressions, with strategy as the independent variable and the status of whether or not the strategy was observed in a trial as the dependent variable, using R (R Core Team, 2012). Across all language groups, we found differences in the rate of strategies for tools $\left(X^{2}=10799.6, d f=2, p<.001\right)$, animals $\left(X^{2}=1041.9\right.$, $d f=2, p<.001)$, and fruits \& vegetables $\left(X^{2}=1149.9, d f=2, p<.001\right)$. For each 
A) MANIPULATION

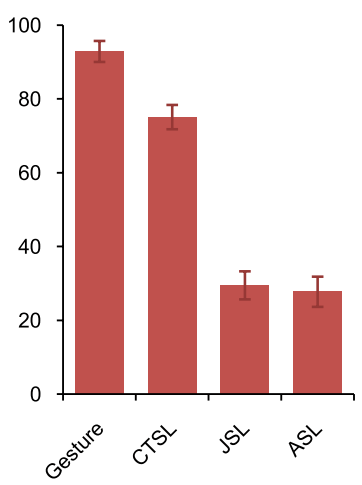

B) PERSONIFICATION

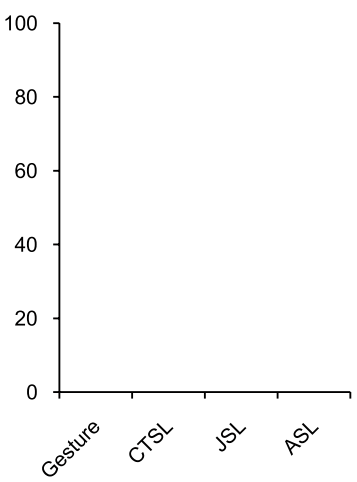

C) OBJECT

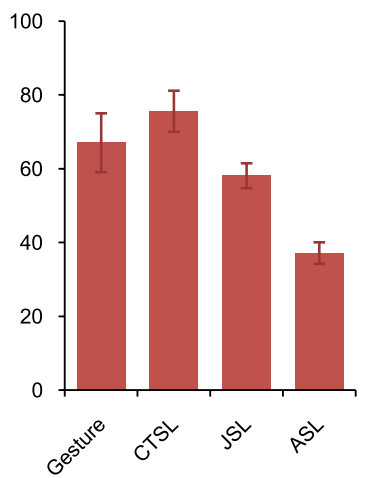

Fig. 9. For the fruits \& vegetables category, two strategies were preferred: овјест and MANIPULATION. We found high rates of MANIPULATION forms in gesture and Central Taurus Sign Language for representing fruits \& vegetables, as compared to Japanese and American Sign Languages. (The values reflect mean averages across eight participants in each group with standard error bars.)

of these semantic categories, we ran Tukey pairwise comparisons between the predicted dominant strategy and the other two. Within the semantic category of tools, the MANIPULATION strategy was statistically higher $(p<.001)$ than the strategies of PERSONIFICATION or OBJECT. Within the semantic category of animals, the PERSONIFICATION strategy was statistically higher $(p<.001)$ than the strategies of MANIPULATION Or OBJECT. Within the semantic category of fruits \& vegetables, MANIPULATION rates and OВJECT rates were higher than PERSONIFICATION rates $(p<.001)$, but not statistically different from each other $(p=.29)$.

We conducted Tukey pairwise comparisons in order to determine whether each group exhibited a preferential pairing of either the MANIPULATION or the овJЕст strategy with the category of fruits and vegetables. MANIPULATION rates were higher than OBJECT rates for Gesture $(p<.001)$, and MANIPULATION rates were not statistically different from овјЕст rates for CTSL $(p=.99)$. In contrast, овјЕСт rates were higher than MANIPULATION rates for JSL $(p<.001)$ and ASL $(p=.02)$.

Consistent with our results regarding the preferential use of MANIPULATION with tool and PERSONIFICATION with animals, we found no statistical differences among the four groups in the rate of MANIPULATION forms for tools $\left(X^{2}=4.1, d f=3, p=.25\right)$ and the rate of personification forms for animals $\left(X^{2}=5.4, d f=3, p=.14\right.$ ). 


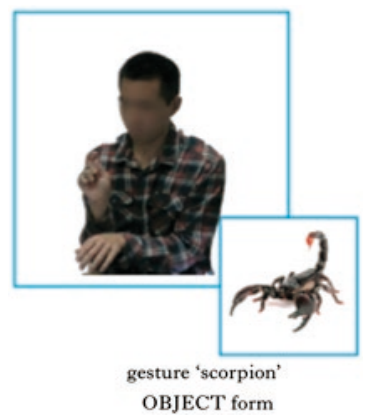

Fig. 10. Example of an овјест form for an animal entity from the gesture of a non-signer.

These results suggest that iconic strategies are patterned robustly across languages for categories like tools and animals, but that a greater degree of variation in use of strategy can be found for categories like fruits \& vegetables.

We further tested the generalizability of these patterns by examining responses in other sign languages to the same test materials, as described in the two following studies, the SINGLE ELICITATION STUDY and the CORPUS STUDY.

\subsection{SINGLE ELICITATION STUDY}

Here, we ask whether our earlier results predict the forms used by a single signer of additional different sign languages, ABSL, ISL, and DGS. We predict that, as young languages, ABSL and ISL should show patterns similar to CTSL, and as an established language, that DGS should show patterns similar to ASL and JSL.

Padden et al. (2013) reported that ABSL uses MAN I P U LAT I ON strategies for representing tools, with a stronger preference for INSTRUMENT forms over HANDLING forms. In the single elicitation study, we found that $100 \%$ of our thirty tool items were represented with MANIPULATION strategies by the ABSL, ISL, and DGS signers (Figure 11a). The ABSL signer used OBJECT forms in sequence with MANIPULATION forms for $17 \%$ of her responses to tools, primarily to indicate size, whereas the ISL and DGS signers did not (Figure 11c).

We next examined the rates of strategies for animals (Figure 12). As with our GROUP ELICITATION STUDY, PERSONIFICATION forms among single signers across sign languages were found only for animals and at the following rates: $62 \%$ in ABSL, 59\% in ISL, and 60\% in DGS. Animals were also represented with object forms: $57 \%$ in ABSL, 48\% in ISL, and 
A) MANIPULATION

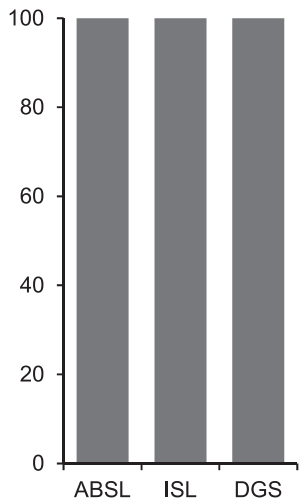

B) PERSONIFICATION

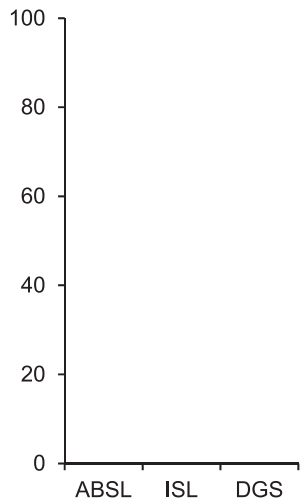

C) OBJECT

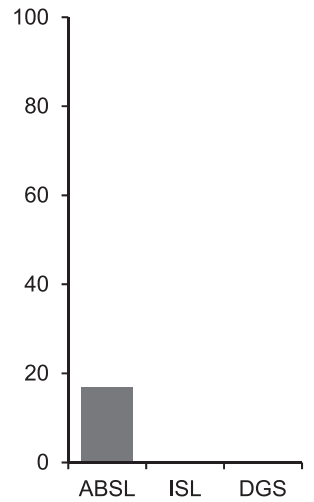

Fig. 11. Graphs demonstrate that the three languages show a preference for MAN I P ULATI I N forms over other forms for representing tools.

$43 \%$ in DGS. MANiPULATI ON forms were used for representing only $3 \%$ of animals in all three signers.

Finally, we examined the rates of strategies for fruits \& vegetables (Figure 13). Ов вест forms were found at the following rates: $60 \%$ in ABSL, 54\% in ISL, and 57\% in DGS. MANIPULATION forms were found at the following rates: $87 \%$ in ABSL, $79 \%$ in ISL, and 50\% in DGS.

In the GROUP ELICITATION STUDY, we compared two established sign languages (ASL and JSL) with a young sign language (CTSL) and the gestures of non-signers. The single-elicitation study allows us to compare another established sign language (DGS) with two other young sign languages (ABSL and ISL). Comparing across studies, we find that, in established and young sign languages alike, MANIPULATION forms are used at a high rate for tools, and similarly that PERSONIFICATION and OBJECT forms are used at high rates for animals. MANIPULATION forms are also used at higher rates for fruits \& vegetables in young sign languages (CTSL, ABSL, ISL) than in established sign languages (ASL, JSL, DGS).

These results confirm the two types of patterns that were found in the GROU P E L I C I TAT I ON STUDY, (i) those that are shared across manual systems (i.e., the preference of using the body to represent an agent using a tool, the preference of using the body to represent the body of an animal), as well as (ii) those that differ across languages, perhaps as a function of language age (i.e., the preference for representing fruits \& vegetables by referencing how they are prepared and eaten, in addition to referencing what they look like). 
A) MANIPULATION

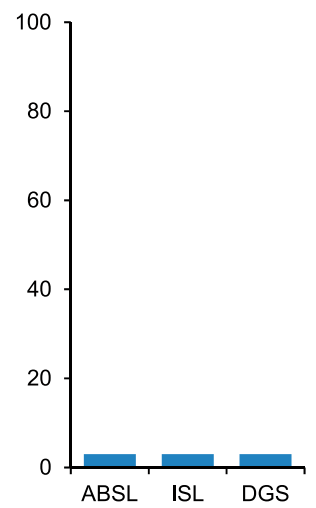

B) PERSONIFICATION

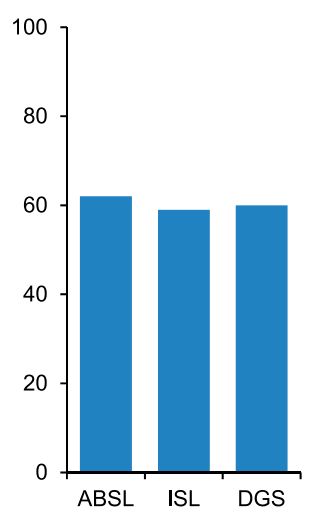

C) OBJECT

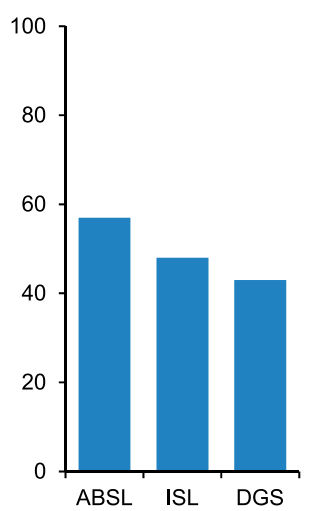

Fig. 12. Graphs demonstrate that the three languages show the highest preference for PERSONIFICATION forms for representing animals, with lower preferences for OBJECT and MANIPULATION forms.

\subsection{Corpus analysis of Kenyan Sign Language and Ha Noi Sign Language}

To confirm that our elicitation results are not contingent on the set of ninety items we selected, we examined corpora data from two additional languages, KSL and HNSL, for signs naming culturally specific entities drawn from the same semantic categories of animals, tools, and fruits \& vegetables. We coded all signs from the corpora data that could be identified as falling into one of these three categories.

The KSL data analyzed here are 152 signs drawn from a larger corpus, with accompanying videos, used to analyze the phonological and morphological structure of KSL (Morgan, 2015). Signs were collected in a rural town in southwestern Kenya that has two deaf schools and an active community of deaf adults. In total, twelve deaf KSL signers participated in the development of the corpus, with three signers (two female) contributing the majority of signs in the database. Only signs that were observed to be used in this region were included, and were elicited in a variety of ways - photographs, illustrations, English translation, and in conversation. Nearly all of these signs analyzed here were elicited from photographs found online that were taken in East Africa. The photographs were presented on a laptop, with a black background and the English word for the target sign visible below the photograph.

The 152 signs consisted of the following numbers for each category: 22 signs for tools (e.g., spoon, plough, shovel, machete, hoe), 83 for animals 
A) MANIPULATION

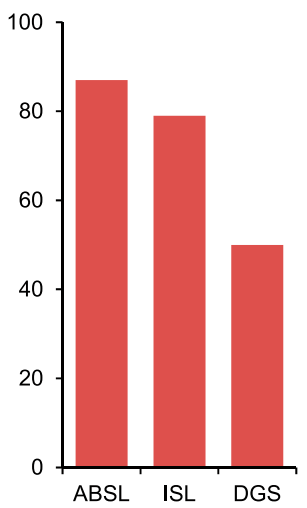

B) PERSONIFICATION

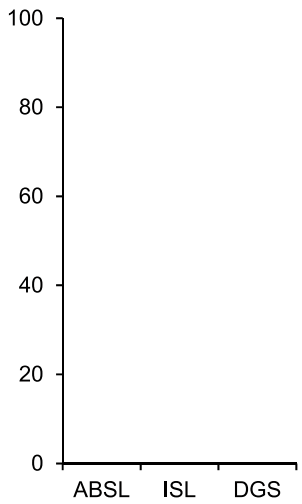

C) OBJECT

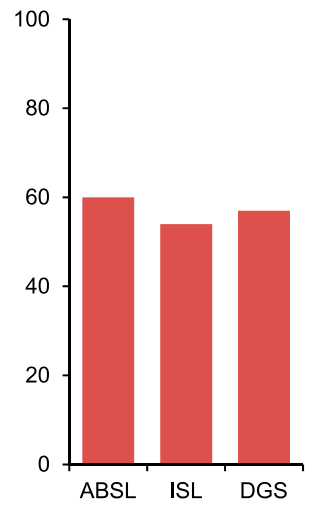

Fig. 13. For the fruits \& vegetables category, two strategies were preferred: овJECT and MANipulation. We found high rates of manipulation forms in ABSL and ISL for representing fruits \& vegetables, as compared to DGS.

(e.g., bat, pig, porcupine, tilapia, hyena), and 47 for fruits \& vegetables (e.g., kale, beans, lemon, maize, sweet-potato).

The HNSL data come from a dictionary created by the Ha Noi Association for the Deaf. The data analyzed here consist of all 156 signs in the dictionary that are relevant to our study: 19 tools, 58 animals, and 79 fruits \& vegetables. The dictionary entries include pictures of the entities, pictures of signers modeling the HNSL sign, with arrows and numbering showing movement sequences, the Vietnamese term for the entity, and an English term for the entity.

Again, the dominant strategy for representing tools was M A N I P U LAT I ON : $100 \%$ of signs for tools in KSL and HNSL depict human action (Figure 14a). We did not find any cases where an о в Ј Е с т form was used to represent a tool in KSL, but we found three such cases $(16 \%)$ in HNSL where an о в JECT form was used with a MANIPULATION form (saucepan, mortar $\xi^{\circ}$ pestle, bucket) (Figure 14c).

Again, animals were the only semantic group represented with PERSONIFICATION forms: 76\% in KSL and 64\% in HNSL (Figure 15b). Animals were also represented with о в Jе с т forms: $20 \%$ in KSL and $57 \%$ in HNSL (Figure 15c). MANIPULATION forms were used to represent only $4 \%$ of animals in KSL, with no examples found in HNSL (Figure 15a). We suspect the lower rate of PERSONIFICATION forms and higher rate of ов Вест forms in HNSL in comparison with KSL may be attributed to the 
CORPUS ANALYSIS

PERCENT OF TOOL CATEGORY REPRESENTED BY:

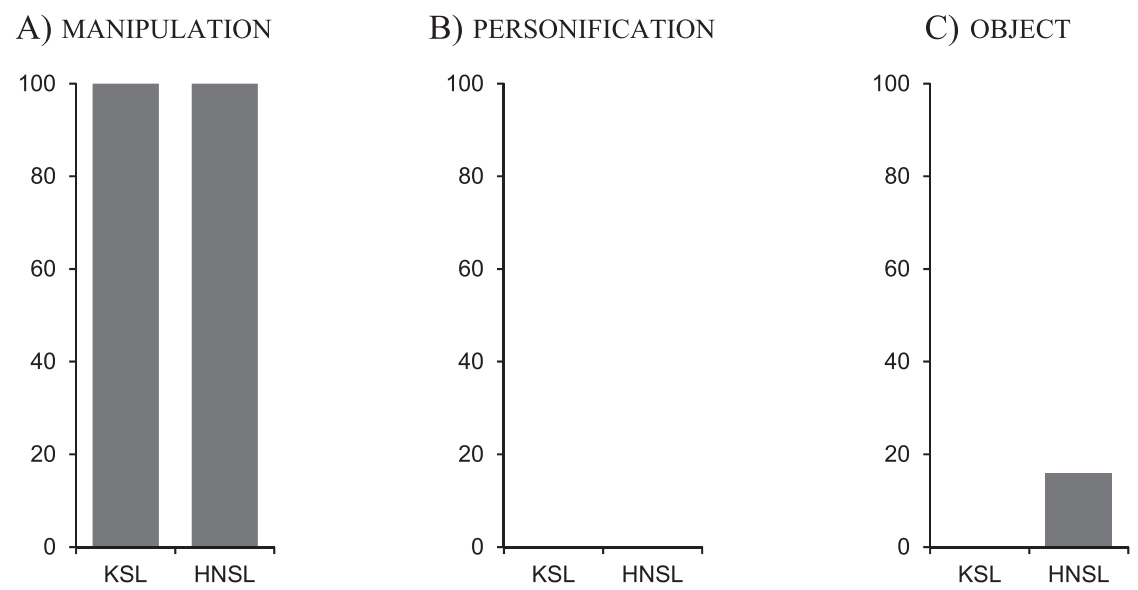

Fig. 14. Graphs demonstrate that both languages show a preference for MANIPULATION forms over other forms for representing tools.

higher number of non-mammalian entities in the HNSL set, which included several different species of fish and birds.

Finally, we analyzed strategies used to represent fruits \& vegetables (Figure 16). We found MAN IP ULAT I ON forms at the following rates: $62 \%$ in KSL and 30\% in HNSL. We found ов вест forms at the following rates: $20 \%$ in KSL and $90 \%$ in HNSL. As we found in the results from the elicitation studies, the category of fruits \& vegetables is not reliably represented with a preferred or dominant pattern across languages, unlike the cross-linguistic association of tools with MANIPULATION forms or animals with PERSONIFICATION forms.

\subsection{RECOGNIZING THE BODY}

The results from the above three studies point to two main findings: (i) the typical use of the body to represent a human agent when identifying and naming tools and fruits \& vegetables, and (ii) the dual role of the body in representing humanness as well as non-human animates, as in gestures and signs for animals.

Representing a human agent through patterned use of the body is seen principally with conventions for naming tools, objects that humans have created and that typically have a small number of intended uses. However, as Gibson (1979) noted, human beings act upon not only the artifacts that they 
A) MANIPULATION

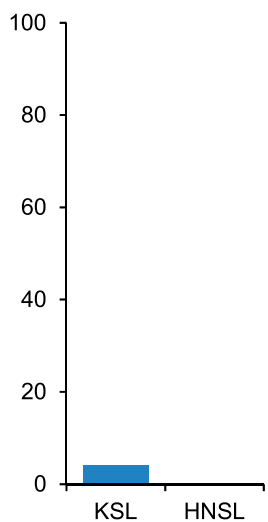

B) PERSONIFICATION

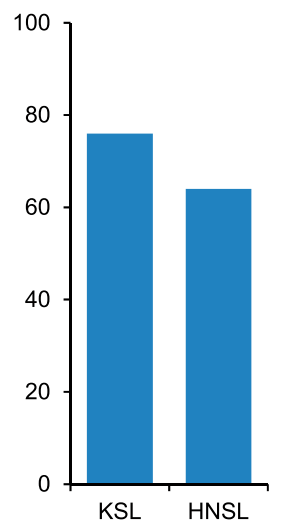

C) OBJECT

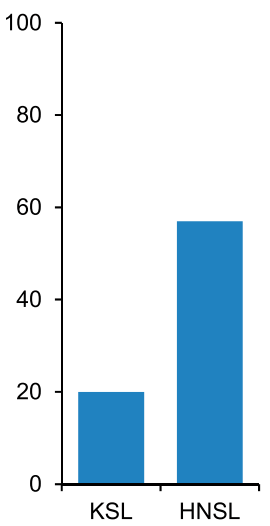

Fig. 15. Graphs demonstrate that both languages show the highest preference for PERSONIFICATION forms for representing animals, with lower preferences for OBJECT and MANIPULATION forms.

themselves have created, but also the natural environment. MAN I P U LAT I ON forms reflect cultured ways of interacting with a diverse set of entities that can be found in the physical environment. MANIPULATION forms are also used to describe human cultivation and consumption of fruits and vegetables. Gesturers and signers of young sign languages used M A I P ULAT I ON forms at high rates (near 90\%) for this class of objects. However, in many cases, MANIPULATION forms that simply show cutting or eating do not help distinguish between objects that are prepared in similar ways. In established sign languages, successful M A N I P U L A T I O N forms are more distinctive: peeling for 'banana', smashing for 'garlic', and thumping for 'watermelon'.

We have also seen a number of cases where MANIPULATION forms are used for animals, as in the controlling of the reins of a 'horse' or the stroking of the (imagined) fur of a 'cat'. Colleagues conducting fieldwork on other sign languages have given us other culturally specific examples: in the " $Z$ " signing community in Mexico, 'chicken' is represented by depicting the motion of snapping the neck of a chicken in preparation for eating (Haviland, 2013), and in the Chatino signing community, also found in Mexico, 'chicken' is represented by depicting the motion of a machete sawing back and forth on the signer's head, also in preparation for eating (personal correspondence, Lynn Hou and Kate Mesh). Thus, M A I P U LAT I O N forms are used in forms where referent objects are associated with canonical actions and reflect cultural practices. 
PERCENT OF FRUITS \& VEGETABLES CATEGORY REPRESENTED BY:

A) MANIPULATION

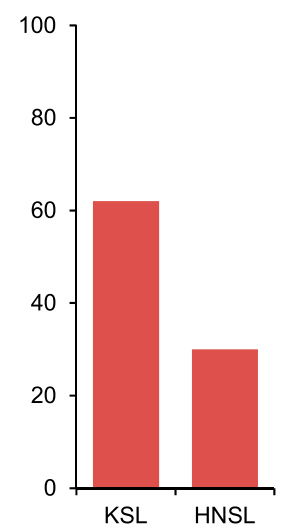

B) PERSONIFICATION

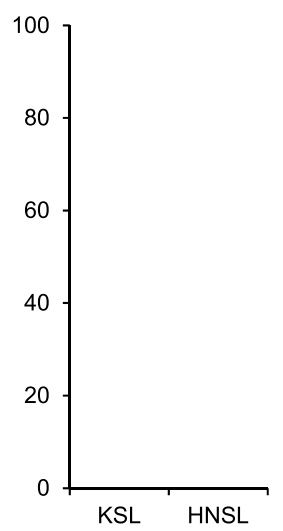

C) OBJECT

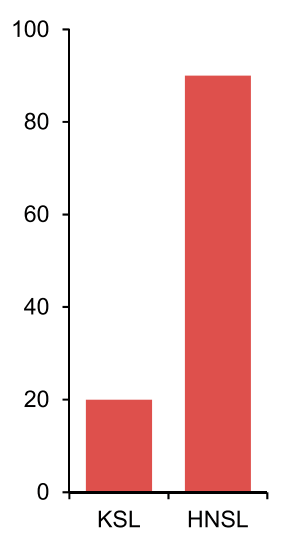

Fig. 16. For the fruits \& vegetables category, two strategies were preferred: овJЕСт and MANIPULATION.

These examples show that many animals can be considered to have "distinctive uses" that set them apart from other referents and so can be represented with a MANIPULATION form. However, for other animals, particularly undomesticated or wild ones, there may not be a characteristic human action. Instead, we find that the body is extended to represent other kinds of bodies. Bodies of land mammals like 'giraffe' and 'elephant' draw on correspondences between an animal body and a human one, using the human hands on the body in order to map the location of an animal's characteristically long neck or long trunk. Smaller animals like fish and spiders, and other, less mammalian animals are often, but not always, represented using овјЕст forms, where animacy is conveyed through a wiggling or scooting movement of the hands and fingers.

Other examples where iconic representations reflect extension of the body are signs for certain fruits \& vegetables in ASL and JSL. These established languages demonstrate an expanded repertoire of body-based iconic strategies, using specific attributes on the head and face without extending the iconic mapping to rest of the body. These mappings involve fewer structural correspondences; rather than using the head to represent a head, complete with two eyes, a nose, and mouth, the head may simply represent a spherical object, as in the JSL sign for 'onion', which involves an upward movement from the top of the head to show the stalk emerging from the top of an onion. 


\section{General discussion}

While recognizing the broad diversity of sign language lexicons, we argue that it is also possible to detect similarities among sign languages through the lens of patterned iconicity. Our investigation of the iconic properties of signs and their similarities to gesture would appear to play into a common myth about sign languages, that they are fundamentally alike. Those without knowledge about sign languages are often surprised to find that there is not a universal sign language (Battison \& Jordan, 1976) or that ASL and British Sign Language (BSL) developed independently of each other, even though their societies share a spoken language. The myth of a universal sign language is rooted in a common belief that communicating with the hands and body is transparent and universal. It is not an unreasonable belief, given the popularity of games like charades, or in events where there is no shared spoken language, as in a foreign market place, where tourists can rely on gesture to carry out basic communication.

Moreover, signers of different sign languages seem to be able to negotiate shared vocabulary in more than a rudimentary fashion (Moody, 1987; Supalla $\&$ Webb, 1995). Owing to an increase in the number of international conferences, associations, sporting events, and other social opportunities to bring together signers of mutually unintelligible sign languages, a system called "International Sign" has emerged for use in one-on-one communication and in large audience presentations at conferences and symposia (McKee \& Napier, 2002). McKee and Napier describe International Sign as allowing for communication among signers who "share common contextual experiences and knowledge of grammatical structures in sign languages, but not a common lexicon” (p. 28).

We argue here that the impression of similarity or "universality" across sign languages and between sign language and gesture is rooted in the powerful ways that the body can be used as a medium of communication. When individual signs across sign languages are compared with one another, they may be quite different: in one sign language, 'dog' may be represented with the hands moving as in a barking mouth; in another, the sign shows the human snapping fingers as if to draw the attention of a dog. But when groups of signs of related semantic concepts, say animals, within and across different languages, are compared, there are systematic iconic patterns within the category. Our studies here show that these patterns can be reliably identified. We propose that this impression of similarity across signs and gestures comes from a ubiquity of patterned iconicity. Here we describe three examples, but we believe there are many more. Recently, Lepic, Börstell, Belsitzman, and Sandler (2016) have compared two-handed signs across different sign language lexicons to show that signs for certain concepts, e.g., plurality and atmospheric events, are more likely than chance to be two-handed. 
Sign languages exhibit linguistic structure at all levels of organization; there is ample evidence of phonological, morphological, and syntactic structure. Furthermore, sign languages convey complex and abstract meanings as spoken languages do (Emmorey, 2002; Sandler \& Lillo-Martin, 2006). Nevertheless, even when acknowledging that sign languages are not pantomime, it is not hard to notice correspondences between spontaneous gesture and conventionalized signs. Ongoing work with emerging and young sign languages, including homesign, has demonstrated in detail the possible origins of vocabulary in established sign languages (Haviland, 2013; Hunsicker \& Goldin-Meadow, 2013; Padden et al., 2013; Tkachman \& Sandler, 2013). There is evidence that iconicity persists in established sign languages as well, despite the presence of complex grammatical structure and natural language processing pressures (Klima \& Bellugi, 1979; Perniss, Thompson, \& Vigliocco, 2010; Meir, Padden, Aronoff, \& Sandler, 2013; Emmorey, 2014). Though here we have focused on lexical signs whose function is to name referent objects, our findings are also broadly compatible with discussions of iconic, spatial predicates in sign languages, commonly referred to as classifier constructions, in which the shape and movement of the hands conveys grammatical information (e.g., Benedicto \& Brentari, 2004; Brentari et al., 2015). To complement these descriptions of grammatical patterns accounting for the configuration and movement of the hands through signing space, our findings here show that it is also necessary to consider the representational role of the body as well as the hands in discussions of iconicity in sign language structure (cf. Taub, 2001; Wilcox, 2004; Emmorey, 2014).

In this paper, we have shown that there are identifiable iconic strategies that can be compared among referential signs across unrelated sign languages. Other investigators have asked to what degree signs across different sign languages are similar or identical to each other (McKee \& Kennedy, 2000; Guerra Currie, Meir, \& Walters, 2002; Al-Fityani \& Padden, 2010), following methods that have been used to study spoken languages (Greenberg, 1957). Using a modified Swadesh list of 100 core concepts, McKee and Kennedy (2000) report that 64 signs are identical in the historically linked British, Australian, and New Zealand Sign Languages. In contrast, only 19 of the signs (19\%) in this group are identical to ASL. Guerra Currie et al. (2002) compare signs in French, Spanish, Mexican, and Japanese Sign Languages, using a list of terms for "foods, flora and fauna, modes of transportation, household objects, articles of clothing, calendrical expressions, professions, kinship terms, wH -words and phrases, and simple emotions" (p. 226). They calculated the percent overlap in the languages based on whether signs shared at least two of the three major parameters of sign formation. They report that $23 \%$ of signs in the dataset are similarly articulated in Mexican and Japanese Sign Languages, the two least related 
languages in their set, with higher rates of similarity for pairwise comparisons between related languages.

Guerra Currie et al. (2002) note that similar rates of overlap are reported in other studies (Woodward, 1978; Woll, 1983; Kyle \& Woll, 1985; Woll, 1987; Smith Stark, 1990). Their observed rates of 20-40\% similarity are relatively high compared to spoken languages. They attribute the degree of similarity to the visual-gestural modality and its iconic affordances, or "shared symbolism".

Focusing on iconic properties of signs, rather than their formational features, Richie et al. (2014) examined the conventionalization of signs in developing lexicons of homesigners in Nicaragua. They coded signs for item-specific iconic properties, which they call "conceptual components". The examples they provide are for 'cow', where the representation of a human agent milking a cow was coded as "milking" and the representation of a cow's horns was coded as "horns". When comparing their coding system to ours, "milking" would be subsumed under our category of M A N I P U L A T I O N. "Horns" would be subsumed under PERSONIFICATION if the horns were represented with hands brought to the side of the head, or as ов ВЕ С $\mathrm{T}$ if the horns were represented away from the body with a single hand, such as with the index finger and pinky extended and the hand itself corresponds to the head of the animal. The item-specific method of coding iconic properties used by Richie and colleagues is useful for their study because they were tracking the degree to which homesigners and their communication partners showed consistency for twenty-two signs, which were not further grouped into semantic categories.

Beyond the domain of lexical patterns, other research groups have reported robust and consistent mappings across sign languages like those reported here. Strickland et al. (2015) found that telicity of verbs is encoded through movement, which involves repetition in atelic verbs and no repetition plus clear event boundaries for telic verbs. The seemingly universal nature of this pattern is attributed to mapping biases that can be found even among non-signers. Brentari et al. (2015) found that handling handshapes are aligned with the description of events involving human agents, and that "object handshapes those that represent the class, size, or shape of objects" are aligned with events of object motion that do not involve human agents. The directionality of these preferences can be found among non-signing gesturers as well.

We have demonstrated here the value of analyzing iconic strategies at the level of lexical semantic categories in sign languages, and of recognizing the representational role of the body in this example of patterned iconicity. From this perspective, the interesting finding is not that signs for 'bird' look similar or different in any two sign languages, but that (i) signs for 'bird' are likely to 
share an iconic strategy with other signs for animals, and (ii) broadly, sign languages use similar strategies to organize their lexicons.

As an initial step toward documenting these strategies, the iconic patterns we have examined in this paper are as follows: tools are overwhelmingly represented through MANIPULATION forms, where the body depicts the body of a human agent. Animals are represented through P E R S O N I F I C A T I O N forms, where the body depicts the body of the animate referent, as well as through ов ВЕСТ forms, where the hands but not the body depict aspects of the animate referent. We have speculated that these two strategies may serve more fine-grained representational functions, such as to distinguish animals that live on land vs. those that live in water, but leave this question for a future investigation. Fruits and vegetables are represented with ов ЕСт forms where the hands depict static aspects of the referent, as well as M A N I P U L A T I O N forms that evoke how agents prepare these entities for human consumption. We have speculated that the use of iconic strategies for fruits \& vegetables may change as a function of language age and conventionalization as established sign languages further differentiate between similar items within a set or category.

Applying a similar methodology of identifying iconic strategies in other parts of lexicons and grammars could lead to the discovery of additional typological tendencies across sign languages. Such investigations promise to contribute to a better understanding of the role of iconicity in language structure. As a result, we hope that discussions on iconicity will go beyond the focus on imagistic properties, or the closeness of form-meaning mappings, to broader aspects of cognitive organization (cf. Gentner, 1983) and the impact of cultured ways of interacting with and relating to entities found in the world.

\section{REFERENCES}

Al-Fityani, K., \& Padden, C. (2010). Sign language geography in the Arab World. In D. Brentari (Ed.), Sign languages: a Cambridge survey (pp. 443-450). New York: Cambridge University Press.

Battison, R., \& Jordan, I. K. (1976). Cross-cultural communication with foreign signers: fact and fancy. Sign Language Studies, 10(1), 53-68.

Benedicto, E., and Brentari, D. (2004). Where did all the arguments go? Argument-changing properties of Classifiers in ASL. Natural Language and Linguistic Theory, 22(4), 743-810.

Boyatzis, C. J., \& Watson, M. W. (1993). Preschool children's symbolic representation of objects through gestures. Child Development, 64(3), 729-735.

Brentari, D., Coppola, M., Mazzoni, L., \& Goldin-Meadow, S. (2012). When does a system become phonological? Handshape production in gesturers, signers, and homesigners. Natural Language \& Linguistic Theory, 30(1), 1-31.

Brentari, D., Renzo, A. D., Keane, J., \& Volterra, V. (2015). Cognitive, cultural, and linguistic sources of a handshape distinction expressing agentivity. Topics in Cognitive Science, 7(1), 95-123.

Brugman, H., \& Russel, A. (2004). Annotating multi-media/multi-modal resources with ELAN. In 4th International Conference on Language Resources and Evaluation (LREC 2004) 
(pp. 2065-2068). Nijmegen: European Language Resources Association, Max Planck Institute for Psycholinguistics, the Language Archive.

Dudis, P. G. (2004). Body partitioning and real-space blends. Cognitive Linguistics, 15(2), 223-238.

Emmorey, K. (2002). Language, cognition, and the brain: insights from sign language research. Mahwah, NJ: Lawrence Erlbaum and Associates.

Emmorey, K. (2014). Iconicity as structure mapping. Philosophical Transactions of the Royal Society of London B: Biological Sciences, 369(1651), DOI: 10.1098/rstb.2013.0301.

Engberg-Pedersen, E. (2004). Review of Language from the body: iconicity and metaphor in American sign language, by Sarah F. Taub. Linguistic Review, 21(1), 67-86.

Ergin, R. (2015). Something out of nothing: a brand new language: TEDx Tufts [Video file]. Online: <https://www.youtube.com/watch?v=RO1cXxEQm-w>.

Gentner, D. (1983). Structure-mapping: a theoretical framework for analogy. Cognitive Science, 7(2), 155-170.

Gibson, J. J. (1979). The ecological approach to visual perception. Boston, MA: Houghton Mifflin.

Goldin-Meadow, S., So, W. C., Özyürek, A., \& Mylander, C. (2008). The natural order of events: how speakers of different languages represent events nonverbally. Proceedings of the National Academy of Sciences, 105(27), 9163-9168.

Goodglass, H., \& Kaplan, E. (1963). Disturbance of gesture and pantomime in aphasia. Brain, 86(4), 703-720.

Greenberg, J. H. (1957). The nature and uses of linguistic typologies. International Fournal of American Linguistics, 23(2), 68-77.

Guerra Currie, A. M., Meier, R., \& Walters, K. (2002). A crosslinguistic examination of the lexicons of four signed languages. In R. Meier, K. Cormier, \& D. Quinto-Pozos (Eds.), Modality and structure in signed and spoken languages (pp. 224-236). Cambridge: Cambridge University Press.

Haviland, J. B. (2013). The emerging grammar of nouns in a first generation sign language: specification, iconicity, and syntax. Gesture, 13(3), 309-353.

Hunsicker, D., \& Goldin-Meadow, S. (2013). How handshape type can distinguish between nouns and verbs in homesign. Gesture, 13(3), 354-376.

Kendon, A. (1980). A description of the deaf-mute sign language from the Enga province of Papua New Guinea with some comparative discussion; Part ii: the semiotic functioning of Enga signs. Semiotica, 32(1/2), 81-117.

Klima, E., \& Bellugi, U. (1979). The signs of language. Cambridge, MA: Harvard University Press.

Kyle, J. G., \& Woll, B. (1985). Sign language: the study of deaf people and their language. Cambridge: Cambridge University Press.

Lepic, R., Börstell, C., Belsitzman, G., \& Sandler, W. (2016). Taking meaning in hand. Sign Language and Linguistics, 19(1), 37-81.

McKee, D., \& Kennedy, G. (2000). Lexical comparison of signs from American, Australian, British and New Zealand sign languages. In K. Emmorey \& H. Lane (Eds.), The signs of language revisited: an anthology to honor Ursula Bellugi and Edward Klima (pp. 49-76). Mahwah, NJ: Lawrence Erlbaum Associates.

McKee, R. L., \& Napier, J. (2002). Interpreting into international sign pidgin: an analysis. Sign Language छे Linguistics, 5(1), 27-54.

Meier, R. P. (2002). Why different, why the same? Explaining effects and non-effects of modality upon linguistic structure in sign and speech. In R. P. Meier, K. Cormier, \& D. Quinto-Pozos (Eds.), Modality and structure in signed and spoken languages (pp. 1-25). Cambridge: Cambridge University Press.

Meir, I., Padden, C., Aronoff, M., \& Sandler, W. (2007). Body as subject. Fournal of Linguistics, 43(3), 531-563.

Meir, I., Padden, C., Aronoff, M., \& Sandler, W. (2013). Competing iconicities in the structure of languages. Cognitive Linguistics, 24(2), 309-343.

Meir, I., Sandler, W., Padden, C., \& Aronoff, M. (2010). Emerging sign languages. In M. Marschark \& P. Spencer (Eds.), Oxford handbook of deaf studies, language and education, Vol. 2 (pp. 267-280). Oxford: Oxford University Press. 


\section{PATTERNED ICONICITY FOR SEMANTIC CATEGORIES}

Moody, W. (1987). International gestures. In J. V. Van Cleve (Ed.), Gallaudet encyclopedia of deaf people and deafness, Vol. $3 S-Z$ (pp. 81-82), Index. New York: McGraw-Hill Book Company Inc.

Morgan, H. E. (2015). Kenyan Sign Language Lexical Database. Paper presented at 'Digging into Signs' Workshop: Developing Annotation Standards for Sign Language Corpora, London, March 2015.

Müller, C., Bressem, J., \& Ladewig, S. H. (2013). Towards a grammar of gestures: a form based view. In Cornelia Müller, Adam Cienki, Ellen Fricke, Silva Ladewig, \& David McNeill (Eds.), Body - language - communication: an international handbook on multimodality in human interaction (pp. 707-703). Berlin: Mouton de Gruyter.

Newport, E. P., \& Supalla, T. (2000). Sign language research at the millennium. In K. Emmorey \& H. Lane (Eds.), The signs of language revisited: an anthology to honor Ursula Bellugi and Edward Klima (pp. 103-114). Mahwah, NJ: Lawrence Erlbaum Associates.

O'Reilly, A. W. (1995). Using representations: comprehension and production of actions with imagined objects. Child Development, 66(4), 999-1010.

Overton, W. F., \& Jackson, J. P. (1973). The representation of imagined objects in action sequences: a developmental study. Child Development, 44(2), 309-314.

Padden, C. A., Hwang, S.-O., Lepic, R., \& Seegers, S. (2015). Tools for language: patterned iconicity in sign language nouns and verbs. Topics in Cognitive Science, 7(1), 81-94.

Padden, C. A., Meir, I., Hwang, S.-O., Lepic, R., Seegers, S., \& Sampson, T. (2013). Patterned iconicity in sign language lexicons. Gesture, 13(3), 287-308.

Perniss, P., Pfau, R., \& Steinbach, M. (2007). Can't you see the difference? Sources of variation in sign language structure. In P. Perniss, R. Pfau, \& M. Steinbach (Eds.), Visible variation: comparative studies on sign language structure, 188 (pp. 1-34). Berlin: Mouton de Gruyter.

Perniss, P., Thompson, R. L., \& Vigliocco, G. (2010). Iconicity as a general property of language: evidence from spoken and signed languages. Frontiers in Psychology, 1, 227, doi: 10.3389/fpsyg.2010.00227.

Pizzuto, E., \& Volterra, V. (2000). Iconicity and transparency in sign languages: a crosslinguistic cross-cultural view. In K. Emmorey \& H. Lane (Eds.), The signs of language revisited: an anthology to honor Ursula Bellugi and Edward Klima (pp. 261-286). Mahwah, NJ: Lawrence Erlbaum Associates.

R Core Team (2012). R: a language and environment for statistical computing. R Foundation for Statistical Computing, Vienna, Austria. Online: <http://www.R-project.org/>.

Richie, R., Yang, C., \& Coppola, M. (2014). Modeling the emergence of lexicons in homesign systems. Topics in Cognitive Science, 6(1), 183-195.

Sandler, W., \& Lillo-Martin, D. (2006). Sign language and linguistic universals. Cambridge: Cambridge University Press.

Shaw, E., \& Delaporte, Y. (2015). A historical and etymological dictionary of American Sign Language. Washington, DC: Gallaudet University Press.

Smith Stark, T. (1990). Una comparación de las lenguas manuals de México y de Brasil. Paper read at IX Congreso Internaciónal de la Asociación de Lingüistica y Filogía de América Latina (ALFAL), at Campinas, Brasil.

Strickland, B., Geraci, C., Chemla, E., Schlenker, P., Kelepir, M., \& Pfau, R. (2015). Event representations constrain the structure of language: sign language as a window into universally accessible linguistic biases. Proceedings of the National Academy of Sciences, 112(19), 5968-5973.

Supalla, T. (1982). Structure and acquisition of verbs of motion in American Sign Language. Unpublished PhD dissertation, University of California at San Diego.

Supalla, T., \& Webb, R. (1995). The grammar of international sign: a new look at pidgin languages. In K. Emmorey \& J. S. Reilly (Eds.), Language, gesture Eீ space (International conference on theoretical issues in sign language research) (pp. 333-352). Hillsdale, NJ: Erlbaum.

Sutton-Spence, R., \& Napoli, D. J. (2010). Anthropomorphism in sign languages: a look at poetry and storytelling with a focus on British Sign Language. Sign Language Studies, 10(4), 442-475. 
Taub, S. F. (2001). Language from the body: iconicity and metaphor in American Sign Language. Cambridge: Cambridge University Press.

Tkachman, O., \& Sandler, W. (2013). The noun-verb distinction in two young sign languages. Gesture, 13(3), 253-286.

Wilcox, S. (2004). Cognitive iconicity: conceptual spaces, meaning, and gesture in signed language. Cognitive Linguistics, 15(2), 119-148.

Woll, B. (1983). The comparative study of different sign languages: preliminary analyses. In F. Loncke, P. Boyes-Braem, \& Y. Lebrun (Eds.), Recent research on European sign languages (pp. 79-91). Lisse: Swets and Zeitlinger.

Woll, B. (1987). Historical and comparative aspects of British Sign Language. In J. Kyle (Ed.), Sign and school: using signs in deaf children's development (pp. 12-34). Clevedon: Multilingual Matters.

Woll, B. (2003). Modality, universality, and the similarities among sign languages: an historical perspective. In A. E. Baker, B. van den Bogaerde, \& O. Crasborn (Eds.), Cross-linguistic perspectives in sign language research (pp. 17-30). Hamburg: Signum Press.

Woodward, J. (1978). Historical bases of American Sign Languages. In P. Siple(Ed.), Understanding language through sign language research (pp. 333-348). New York: Academic Press.

Woodward, J. (2000). Sign languages and sign language families in Thailand and Viet Nam. In K. Emmorey \& H. Lane (Eds.), The signs of language revisited: an anthology to honor Ursula Bellugi and Edward Klima (pp. 23-48). Mahwah, NJ: Lawrence Erlbaum Associates.

Woodward, J., Nguyen, T. H., \& Tien Nguyen, N. T. (2004). Providing higher educational opportunities to deaf adults in Viet Nam through Vietnamese sign languages: 2000-2003. Deaf Worlds, 20(3), 232-263. 